\title{
Environmental Management in Republic of Crimea Represented by Modeling Use of Big-Diameter Pipelines in Various Operation Modes
}

\author{
M.A. Bandurin \\ Doctor of Technics, associate professor \\ FSBEI HE Platov South-Russian State Polytechnic \\ University (NPI) \\ Novocherkassk, Rostov region, Russia \\ chepura@mail.ru
}

\author{
A.A. Mykhailin \\ Candidate of Technics, associate professor \\ FSBEI HE Platov South-Russian State Polytechnic \\ University (NPI) \\ Novocherkassk, Rostov region, Russia \\ 1andreymih@gmail.com
}

\author{
V.V. Nefedov \\ Candidate of Technics, associate professor \\ FSBEI HE Platov South-Russian \\ State Polytechnic University (NPI) \\ Novocherkassk, Rostov region, Russia \\ nvvnpi@gmail.com
}

\begin{abstract}
The paper features results of modeling of operating conditions of big-diameter pipelines used for water supply of Crimea. The Russian Federation is a constant member of the group of states having a large share in water resources. $10-15 \%$ of total water resources are distributed through the most developed regions in the European part of the country with $80 \%$ of population and production capacities. Federal districts differ widely in the range of local and incoming water resources, and North Caucasian and Southern Federal districts have the lowest water supply. The most water deficient region is the Crimea, where the most rivers are overregulated and serve for the purposes of water supply and watering. The Crimea counts 22 huge barrier basins with a total volume of $334.200 \mathrm{mln} \mathrm{m3}$, a natural discharge volume of $188.920 \mathrm{mln} \mathrm{m} 3$, or $20 \%$ of the whole surface runoff of the Crimea. The barrier basins are filled during the autumnwinter season, during spring floods and sometimes - in the summer - due to excessive rainfalls. Today the off-channel basins of the North Crimean canal with volume $146.350 \mathrm{mln} \mathrm{m} 3$ are filled on a year-round basis from the Biyuk-Karasu river and underground sources. A solid-body model of pipeline basic elements is developed as a result of the experiment. Stress-strain state of the pipeline is analyzed in various combinations of loads. As the result of numerical experiments, the authors could define zones of occurrence of defects and damages on the basic elements. The zones can bear similar types of characteristic damages, which provides for harmonization of the ground penetration test profile laying procedure and definition of points for the necessary measurement of concrete strength at on-site inspections and tests. Calculation of stress-strain state supposed creation of an adequate calculation model under various operating conditions. The number of elements and nodes of the ensemble is, respectively, 73419 and 53429. Coding of initial information occurs in terms of the incremental method with due regard for presentation of pipeline fragments as objects with a simple geometric shape plates.
\end{abstract}

Keywords—hydrotechnical structures, waterworks, big-diameter pipelines, stress-strain state, numerical computing methods, solid model, water conservation, reliability parameters, operating conditions.

\section{I.INTRODUCTION}

The Russian Federation is a constant member of the group of states having large share in water resources. The total volume of static water resources is approximately 88.9 thousand $\mathrm{km} 3$ of fresh water with a major share collected in underground water basins, lakes and glaciers. According to the new data, long-term average annual renewable water resources constitute 4258.6 $\mathrm{km} 3 /$ year. $10-15 \%$ of total water resources are distributed through the most developed regions in the European part of the country with $80 \%$ of population and production capacities [1]. Federal districts differ widely in the range of local and incoming water resources. Thus, for instance, North Caucasian and Southern Federal districts have the lowest water supply. They receive water through water-supply and irrigation facilities as follows: Kuban-Yegorlykskaya, Kuban-Kalausskaya, NizhneDonskaya, Tersko-Kumskaya irrigation facility. Thus, for instance, withdrawal of water in the Southern Federal district was equal to about $12,00539 \mathrm{~km} 3$ in 2013 , including use of water for the purposes of production $-22 \%$, for drinking and household needs $-10 \%$, for watering $-40 \%$, while water losses at transportation constituted $28 \%$, which is more than $1 / 4$ of the total volume of withdrawal. Water withdrawal in the North Caucasian Federal district was equal to about $11.37623 \mathrm{~km} 3$ accordingly, including use of water for the purposes of production $-27 \%$, for drinking and household needs $-8 \%$, for watering $-34 \%$, while water losses during transportation constituted $31 \%$, i.e. every third liter of precious water does not make it to the end consumer. Even in the Crimea, which is the 
most profound in water economy, spending less than $100 \mathrm{~m} 3$ per one person, the losses are still more than $25 \%$ [2].

The deviation of water resources from long-term average annual value for the Southern Federal district is $6.5 \%$ in 2014 against $11.6 \%$ in 2013. A rapid fall in outflow of the Volga River changed the character of water content in regions that are close to Volga (Astrakhan and Volgograd regions) and decreased their water content to the values lower than norm, respectively, by $5.8 \%$ and $8.4 \%$ [3]. Rapid growth of outflow in the left arm of the Kuban River that provided for a restore of outflow of the Kuban River to its normal value. And the same rapid decrease in outflow of rivers along the Black Sea coast led to a relative small change in the water content of Krasnodar region with an increase in the long-term average annual value by $8.7 \%$ against $9.6 \%$ in 2013 . Water resources of the Crimea were significantly lower than the long-term average annual value as compared to 2013, when they were exceeding it by 50 $\%$. The local outflow of rivers in the Crimea Republic (in 2014) did not change and remained on a relative low level $(38.1 \%$ of the norm value). Decrease in water resources takes place due to an unprecedented cut-down of water supply of the peninsula through the North Crimean canal [4].

North Caucasian Federal district has a tendency to a certain decrease in water content of rivers compared to the value that exceeds the norm by $12.1 \%$ in 2013 and to the value that is close to the norm $(4.3 \%)$. The change of water contents widely differs in various territorial entities of the district. Decrease in water contents up to the values that are significantly lower than the norm was reported in two republics - Dagestan and Ingush Republic. The water content pattern of the rivers in the North Caucasus contradicted to the pattern of 2014, which was characterized by the fact that the river flows on the northern slope of the Greater Caucasus Mountain Range are gradually decreasing from the west to the east, from increased values to values that were significantly lower than norm [5]. Earlier, the natural pattern of distribution of water resources was largely disturbed by large-scale interbasin and intrabasin diversion.

General decrease in space of amelioratory grounds is registered in the south of the Russian Federation [6], which is preceded by the problem of water scarcity as well as deteriorating waterworks, which inherently leads to multiplication of emergency situations in absence of highlyneeded qualified staff and technical service facilities.

This is a reason to search for new contemporary methods of quantitative evaluation of security and remaining resource of continuously used waterworks [7] for their proactive maintenance and prevention of their further decay.

The most acute state of water supply is reported in the Crimea where the most rivers are overregulated by barrier basins and are being used for the purposes of water supply and watering [8]. Schastlivenskoye, Ayanskoye and Partizanskoye barrier basins are constructed at the upper reaches of Ayan, Alma and Uzen-Bash rivers for water supply of Simferopol and Yalta. There are more than 50 salt lakes along the coastline that are used for production of salt and healing muds; the biggest lake of that kind is Sasyk-Sivash with an area of $205 \mathrm{~km}^{2}$ [9].
There are 22 huge barrier basins in the Crimea with a total volume of $334.200 \mathrm{mln} \mathrm{m} 3$, natural discharge volume of $188,920 \mathrm{mln} \mathrm{m} 3$, or $20 \%$ of the whole surface runoff of the Crimea [10]. The barrier basins are filled during the autumnwinter season, during spring floods and sometimes - in summer - due to excessive rainfalls. Today the off-channel basins of the North Crimean canal with a volume of $146.350 \mathrm{mln} \mathrm{m} 3$ are filled on a year-round basis from the Biyuk-Karasu river and underground sources [11].

The most water-stressed region is the eastern Crimea - the city of Kerch, Feodossia-Sudak region as well as communities of Leninski district. Filling of off-channel basins is performed by reallocation of water volumes from Belogorskiy and Tayganskiy barrier basins [12] along the stream bed of the Biyuk-Karasu River through the constructed complex of waterworks in the North Crimean canal followed by pumping into off-channel basins.

The dynamics of actual volumes of off-channel basins of the North Crimean canal in 2015 was not more than $50 \%$ and even less in some barrier basins (Mezhgornoye - 12\%, Zelenoyarskoye $-40 \%$ ). The total volume of water intake from natural sources was $253.46 \mathrm{mln} \mathrm{m3}$ in 2015 , while, compared to 2014 , the total volume of water intake from natural sources decreased by $56,86 \mathrm{mln} \mathrm{m} 3$. It is basically due to the following factors: the accumulated Dniepr water from the North Crimean canal was used for the purposes of chemical industry in 2014; the resource was not used in 2015 due to the cut-off of Dniepr water from the North Crimean canal [13]. The values of water intake also did not include the water volumes of the areal redistribution of surface water run-off into water-stressed regions of the Crimea in 2015. The use of water in 2015 constituted $232.73 \mathrm{mln} \mathrm{m} 3$ with conveyance losses of $17.69 \mathrm{mln}$ $\mathrm{m} 3$, which is almost five times lesser if compared to the data of 2014. $12.67 \mathrm{mln} \mathrm{m} 3$ were used for the purposes of agriculture, $181.83 \mathrm{mln} \mathrm{m} 3$ - for housing and utilities and 14,0 $\mathrm{mln} \mathrm{m} 3-$ for manufacturing industry [14].

\section{II.MATERIALS AND METHODS}

Modern reliable use of aquiferous systems is secured by a high level of project developments, construction and effective operation maintained by high-qualified staff. This makes the search for new modern methods a necessary tool to address this issue [15].

The main source of water in the Russian Federation is river discharge that is shaped in the limits of the country, and only $5 \%$ of water comes from the territory of neighbor states. $80 \%$ of the population of the Russian Federation lives in the KaspiyAzov region, constituting only about $8 \%$ of the overall territory and having a main share in business infrastructure. Outflow of rivers on the developed areas is about $800 \mathrm{~km} 3 /$ year (with longterm average annual water resources of the Russian Federation being equal to $4260 \mathrm{~km} 3 /$ year), including the most populated and economically developed regions of the European part of the Russian Federation - only 360 km3/year [16].

Today more than $80 \%$ of waterworks in the south of the Russian Federation are significantly beyond their statutory service life, which is due to the issue of water scarcity and deteriorating waterworks. The conditions will definitely result 
in increase of malfunctioning in view of absence of the necessary high-qualified staff and proper facilities for technical maintenance.

This problem demands for a search of new and modern methods to define quantitative evaluations of reliability and remaining operating life of long-time utilized waterworks [17] for the purposes of their proactive maintenance and prevention of their further decay.

Remaining operating life of water conveying facilities allows setting a safe operating lifetime with or without limitations or taking the decision about overhaul or demolishing of waterworks or their parts or elements. The existing methods describing survey procedures for water conveying facilities are aimed at overall evaluation of suitability of basic structures of the facilities for their further use. A series of questions arises during the survey of the character of fault identification and localization as well as during forecasting of technical state for a certain period of time.

One of the ways to solve the problem could be the use of new modern materials like polyethylene big-diameter pipelines produced by extrusion molding of a composition of thermoplastic materials.

The first and most important advantage of such constructions is their corrosion resistance. Because of this feature, they can be used for a significantly longer time without overhaul. Polyethylene water-supply pipelines also cannot be subject to electrochemical corrosion. Their internal part is smooth, which allows for a significant increase in carrying capacity. Even after many years of using, polyethylene pipelines are distinguished by a significantly better capacity than metallic pipelines. This is due to the fact that polyethylene walls do not accumulate any deposits. Molded pieces may be made not only of plastics but also of metal [18]. Further, no condensate products remain on their surfaces.

Polyethylene big-diameter pipelines have several important advantages over metallic models: production, installation and use of plastic pipes are more cost-efficient, compared to metallic ones. If water freezes inside, it will not lead to any negative outcomes. Plastic pipes weigh significantly less, and that is why their transportation and installation are easier. The polyethylene pipe is technically safe and non-toxic. One does not need to be concerned about transportation because the pipes do not belong to the category of hazardous goods. Plastic pipes are resistant to friction and strain. Their connections are more reliable and robust, which results in extended operating life of the pipes.

The finite element method has exclusive priority in the calculating theory of constructions; its generalization - superelement method - provides for a natural introduction and description of the idea of hierarchically constructed complex systems. In the existing schemes, using three-dimensional isoparametric finite elements, displacements of points are given in the global, as a rule, Cartesian coordinate system. Deformation components are calculated in reference to the permanent global basis. Required accuracy is achieved due to grid thickening. It is useful to distribute the existing standard scheme upon the case, when stress-strain state is defined in local axes of an element, corresponding to the main anisotropy directions of material.

Interpolation polynomial for voluminous structures is written down as a linear function:

$$
\varphi=a 1+a 2 x i+a 3 y i+a 4 z i \text {. }
$$

Unknown coefficients are defined according to the conditions in the nodes:

$$
\begin{aligned}
& \Phi i=a 1+a 2 X i+a 3 Y i+a 4 Z, \\
& \Phi j=a 1+a 2 X j+a 3 Y j+a 4 Z j ; \\
& \Phi k=a 1+a 2 X k+a 3 Y k+a 4 Z k ; \\
& \Phi l=a 1+a 2 X l+a 3 Y l+a 4 Z l .
\end{aligned}
$$

Formulas (2-5) show how finite elements unite and cover the researched area, and interpolating functions can be expressed in terms of values in global nodes having global coordinates. They are introduced instead of general coordinates $\mathrm{i}, \mathrm{j}, \mathrm{k}$; the form is used when there is a need in the minimization process, which is combined with the differentiation of matrices of the elements. It is basically applied during realization of the method of finite elements in digital computing.

\section{III.FINDINGS AND DISCUSSION}

Calculation of stress-strain state implies definition of a computing model that would be applicable for different performance parameters. The number of elements and nodes of the ensemble is, correspondingly, 73419 and 53429. Coding of initial information in terms of the incremental method with due regard for presentation of pipeline fragments as objects with a simple geometric shape - plates [19].

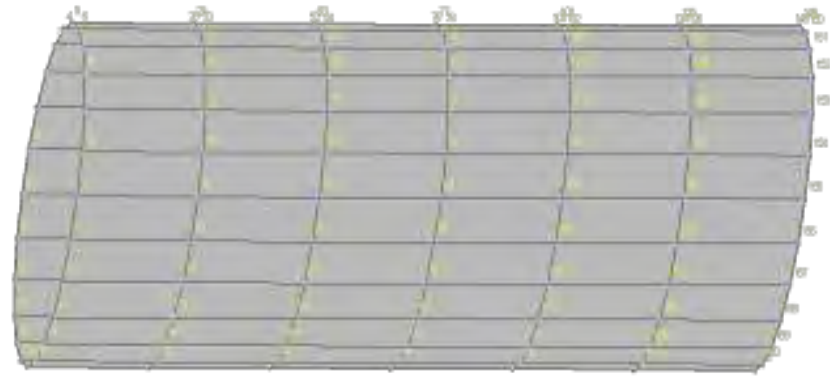

Fig. 1. Finite-element model of a fragment of the polyethylene pipeline.

The aim of setting of numerical computation of the pipeline without characteristic defects was to define adequacy of the solid-body model of stress-strain state of the pipeline at a maximum height with the actual field tests.

The normal stress values during the field test under full load of the pipeline are $2.74 \cdot 107^{\circ} \mathrm{N} / \mathrm{m} 2$ [20], in numerical computation of pipeline modeling $-2.28 \cdot 107^{\circ} \mathrm{N} / \mathrm{m} 2$, which constitutes the difference of less than $10 \%$ and substantiates adequacy of the solid-body model of stress-strain state of the pipeline.

The maximum stresses are created in the support points of the pipeline positioned on anchor feet because of the fact that this fragment functions is a bearer that is rigidly mounted on the 
supports. Stresses in the lower part of the supporting arise horizontally, while vertical stresses along the fragment are registered mainly on flanks in the lower part of the support and in the middle point of the aperture of the pipeline fragment.

Processing of the results of modeling shows insignificant displacements in horizontal (Figure 2, a) and in vertical planes (Figure 2, b) along the fragment, which provides evidence for a wide margin of strength of the pipeline construction [21].
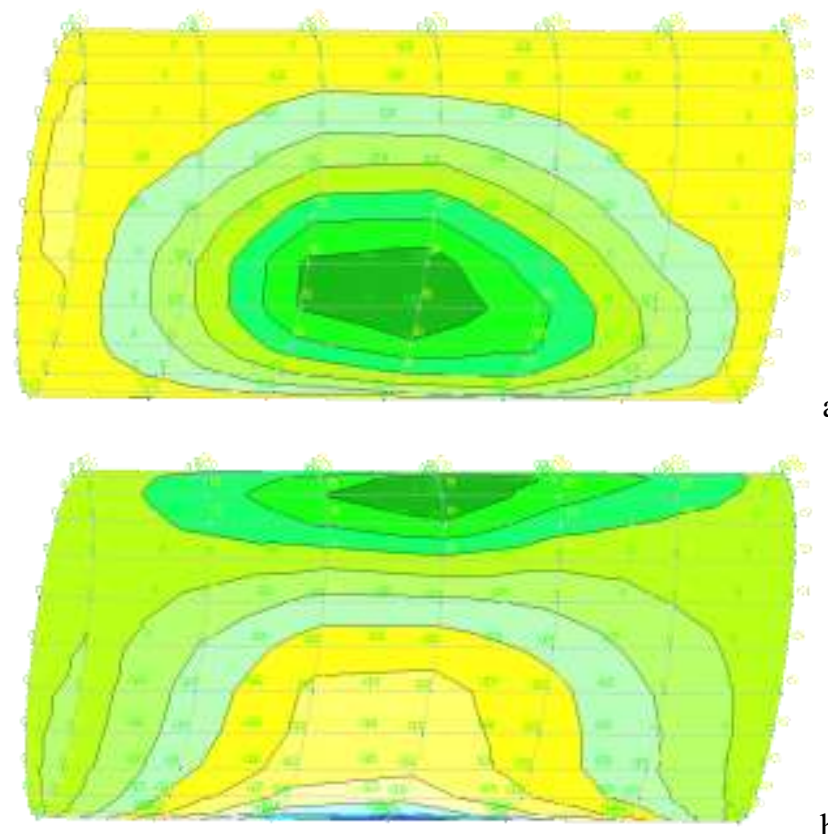

$\mathrm{b}$

Fig. 2. Displacement profiles: a) horizontal; b) vertical.

If the thickness of pipeline walls decreases by $1 / 3$ compared to its initial value, the stress increases significantly leading to bigger displacements. Comparison of equivalent displacement profiles according to von Mises with displacement profiles with thickness decreased by $1 / 3$ for a long period of operation shows occurrence of significant stresses along the perimeter with particular presentation of the zone from 1.5 to $2 \mathrm{~m}$ from the edge of the pipeline (see Figure 3).

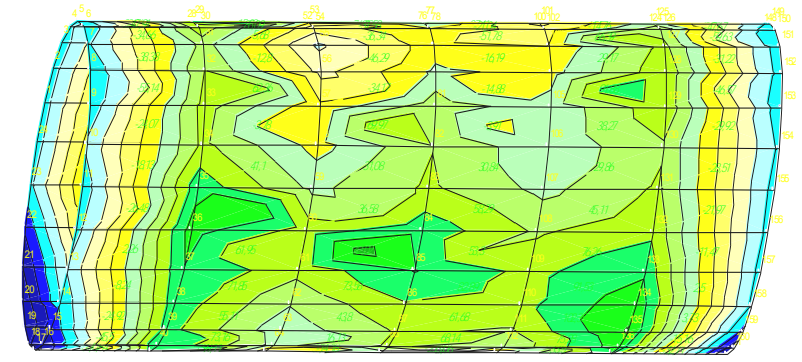

a

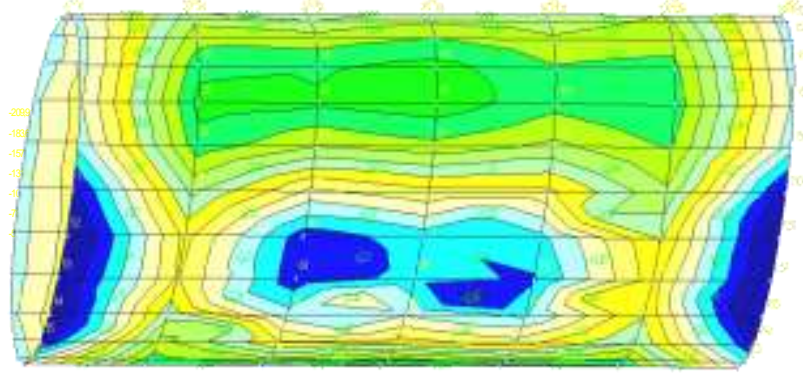

$\mathrm{b}$

Fig. 3. Equivalent stress displacement profile according to von Mises: a) horizontally along the fragment; b) vertically along the fragment.

This peculiarity of modeling is confirmed by visual examination of various defects and damages of long-time operated pipelines as follows: the defects are registered in this zone, which leads to disruption of the pipeline. Processing of the obtained data shows that the most dangerous event is a decrease of actual wall thickness by more than $1 / 3$ of the project thickness, which leads to malfunction of separate fragments of the construction. Cases of insignificant decrease of thickness on displacement profiles show characteristic admissible values [22]. The study registered mainly the defects that would lead to malfunction of water conveying pipelines. This resulted in an intensive water loss, followed by accelerated disruption of the given sector due to subsidence of the underlying terrain and further collapse of the pipeline.

The total displacement profile (Figure 4, a) shows occurrence of maximum displacements in places of deflection of the pipeline along its length, as well as inward constriction of its flanks [23].

Excessive equivalent stress is registered around various small defects (with a diameter from $5 \mathrm{~mm}$ to $15 \mathrm{~mm}$ ) during modeling (see Figure 4, b), which does not significantly affect operation of the entire 12-meter long fragment of the pipeline. A timely maintenance makes it possible to restore operating capacity of the pipeline and eliminate further water losses [24]. 


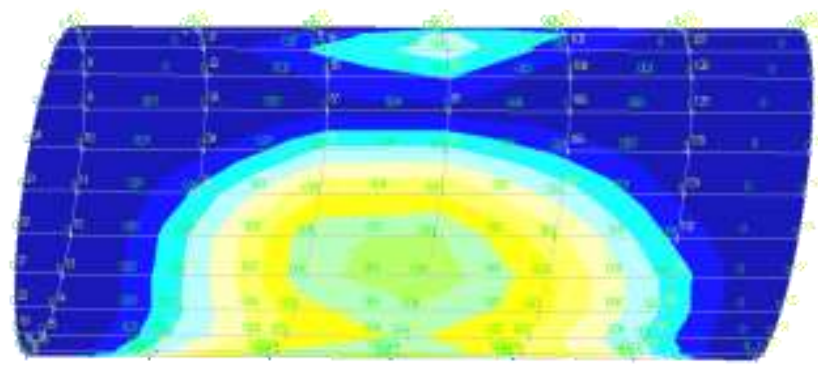

a

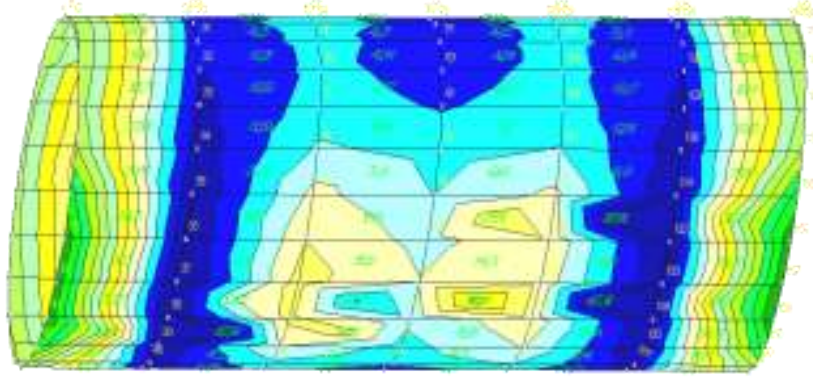

b

Fig. 4. Distribution of: a) total displacements; b) excessive equivalent stress according to von Mises.

\section{IV.CONCLUSION}

The authors have arrived at the following empirical dependences:

group 1 - no defects:

$\mathrm{GV}=0.000141 \mathrm{a} 2+0.0131 \mathrm{a}+3.385 ; \mathrm{R} 2=0.97$;

group 2 - first aperture with lesser thickness:

$\mathrm{GV} Э=-0.3074 \mathrm{a} 2+38.125 \mathrm{a}-218.7 ; \mathrm{R} 2=0.98$;

group 2 - second aperture with lesser thickness:

$\mathrm{GV} Э=-0.657 \mathrm{a} 2+41.565 \mathrm{a}-559.8 ; \mathrm{R} 2=0.95$;

group 2 - third aperture with lesser thickness:

$\mathrm{GV} Э=-0.085 \mathrm{a} 2+16,351 \mathrm{a}-238.1 ; \mathrm{R} 2=0.94$.

Zones of the pipeline, which may feature similar characteristic damages, are defined on the basis of conducted numerical experiments. This provides for harmonization of the ground penetration test profile laying procedure and definition of points for the necessary measurement of pipeline thickness during on-site inspections and tests.

\section{References}

[1] B.P. Chesnokov, O.V. Naumova, V.A. Strelnikov, F.K. Abdrazakov, B.A. Tronin, "Polyethylene production from granules using high voltage", International Journal of Applied Engineering Research, vol. 11, pp. 2140 2144, 2016.

[2] I.V. Sharikova, "Land use of agricultural enterprises: problems, trends, prospects (by the example of the Saratov region)", J. National interests: priorities and security, vol. 4(337), pp. 52, 2016.
[3] V.N. Shchedrin, S.M. Vasilev, A.V. Kolganov, L.N. Medvedeva, A.A. Kupriyanov, "Meliorative institutional environment: the area of state interests", Espacios, vol. 39(12), p. 28, 2018.

[4] I.F. Khitskov, "Problems of sustainable (balanced) development of agrarian - natural systems of the Central Black Earth region", J. Vestnik VSU, Series Economics and Management, vol. 4, pp. 36-43, 2015.

[5] N.F. Ryzhko, F.K. Abdrazakov, S.N. Ryzhko, S.V. Botov, "The increase of qualitative indicators during watering with multiple support sprinklers", Journal of Fundamental and Applied Sciences, vol. 10(6S), pp. 1482-1497, 2018.

[6] I.F. Yurchenko, "Information support system designed for technical operation planning of reclamative facilities", Journal of Theoretical and Applied Information Technology, vol. 96(5), pp. 1253-1265, 2018.

[7] O.G. Degtyareva, D.A. Dac'o, G.V. Degtyarev, A.D. Gumbarov, "Design in cae system of low-head weir tiled foundation sinking", Proceedings of the Kuban State Agrarian University, vol. 64, pp. 221-226, 2017.

[8] M.A. Bandurin, A.A. Mihailin, V.V. Nefedov, "Strength analysis of kinked curve plate used as element of system of deformers in soil cultivators", Advances in Engineering Research, vol. 158, pp. 157-164, 2018.

[9] V.V. Vasiliev, "Optimization of the use of resources in the operation of reclamation systems", J. Bulletin of the Belarusian State Agricultural Academy, vol. 3, p. 151, 2015.

[10] I.F. Yurchenko, "Methodological basis for the creation of an information management system for water use in irrigation", Bulletin of Russian Agricultural Science, vol. 1, pp. 13-17, 2017.

[11] V.N. Shchedrin, S.M. Vasiliev, V.V. Slabunov, "The basic rules and regulations for the operation of reclamation systems and structures, water accounting and production operations: monograph", Novocherkassk: Helikon, p. 657, 2013.

[12] M.A. Bandurin, V.A. Volosukhin, A.V. Mikheev, Y.V. Volosukhin, I.P. Bandurina, "Finite element simulation of cracks formation in parabolic flume above fixed service live”, IOP Conference Series: Materials Science and Engineering, 327(2), 2018, 022010.

[13] L.V. Kireicheva, Scientific foundations of creation and management of reclamation systems in Russia, Moscow: FGBNU VNII agrokhimii, p. 296, 2017.

[14] L.V. Kirejcheva, "New technologies of designing, substantiation of construction", operation and management of land reclamation systems, Moscow: VNIIA, p. 240, 2010.

[15] I.F. Yurchenko, "Information support system designed for technical operation planning of reclamative facilities", Journal of Theoretical and Applied Information Technology, vol. 96(5), pp. 1253-1265, 2018.

[16] I.F. Yurchenko, "Information support for decision making on dispatching control of water distribution in irrigation", Journal of Physics: Conference Series International Conference Information Technologies in Business and Industry 2018 - Mathematical Simulation and Data Processing, 2018, 042063.

[17] I.P. Gaslikova., L.M. Gokhberg, "Information Technology in Russia", Moscow, p. 187, 2002.

[18] A.S. Hmelyak, "Information systems of enterprise management: positive and negative aspects of implementation", Actual questions of economic sciences, vol. 35, pp. 186-182, 2013

[19] I.F. Yurchenko, "Automatization of water distribution control for irrigation", International Journal of Advanced and Applied Sciences, vol. 4(2), pp. 72-77, 2017.

[20] F.K. Abdrazakov, N.F. Ryzhko, S.N. Ryzhko, S.A. Horin, S.V. Botov, "Electricity consumption decrease at pump stations during watering by multi-support sprinkling units", Journal of Fundamental and Applied Sciences, vol. 10(6S), pp. 1464-1481, 2018.

[21] V.I. Olgarenko, I.V. Olgarenko, V.I. Selyukov, "Computer technology of planning water use in irrigation systems", Bulletin of the Russian Academy of Agricultural Sciences, vol. 4, pp. 12-15, 2012.

[22] V.I. Olgarenko, G.V. Olgarenko, I.V. Olgarenko, "Integrated assessment of the technical level of the irrigation and drainage systems", Melioration and water management, vol. 6, pp. 8-11, 2013. 
23] I.F. Yurchenko, "Information systems of managing water economy ameliorative complex", Bulletin of Russian Agricultural Science, vol. 1, pp. $12-15,2016$

[24] F.K. Abdrazakov, S.S. Orlova, T.A. Pankova, E.N. Mirkina, O.V. Mikheeva, "Risk assessment and the prediction of breakthrough wave during a dam accident”, Journal of Interdisciplinary Research, vol. 8(1) pp. 154-161, 2018. 